\title{
Approximation of the common minimum-norm fixed point of a finite family of asymptotically nonexpansive mappings
}

\section{H Zegeye ${ }^{1}$ and N Shahzad ${ }^{2 *}$}

"Correspondence:

nshahzad@kau.edu.sa

${ }^{2}$ Department of Mathematics, King

Abdulaziz University, P.O. Box 80203

Jeddah, 21589, Saudi Arabia

Full list of author information is

available at the end of the article

\begin{abstract}
We introduce an iterative process which converges strongly to the common minimum-norm fixed point of a finite family of asymptotically nonexpansive mappings. As a consequence, convergence result to a common minimum-norm fixed point of a finite family of nonexpansive mappings is proved.

MSC: 47H09; 47H10; 47J05; 47J25
\end{abstract}

Keywords: asymptotically nonexpansive mappings; minimum-norm fixed point; nonexpansive mappings; split feasibility problem; strong convergence

\section{Introduction}

Let $K$ and $D$ be nonempty closed convex subsets of real Hilbert spaces $H_{1}$ and $H_{2}$, respectively. The split feasibility problem is formulated as finding a point $\bar{x}$ satisfying

$$
\bar{x} \in K \text { and } A \bar{x} \in D \text {, }
$$

where $A$ is bounded linear operator from $H_{1}$ into $H_{2}$. A split feasibility problem in finite dimensional Hilbert spaces was first studied by Censor and Elfving [1] for modeling inverse problems which arise in medical image reconstruction, image restoration and radiation therapy treatment planing (see, e.g., [1-3]).

It is clear that $\bar{x}$ is a solution to the split feasibility problem (1.1) if and only if $\bar{x} \in K$ and $A \bar{x}-P_{D} A \bar{x}=0$, where $P_{D}$ is the metric projection from $H_{2}$ onto $D$. Set

$$
\min _{x \in K} \varphi(x):=\min _{x \in K} \frac{1}{2}\left\|A x-P_{D} A x\right\|^{2} .
$$

Then $\bar{x}$ is a solution of (1.1) if and only if $\bar{x}$ solves the minimization problem (1.2) with the minimum equal to zero. Now, assume that (1.1) is consistent (i.e., (1.1) has a solution), and let $\Omega$ denote the (closed convex) solution set of (1.1) (or equivalently, solution of (1.2)). Then, in this case, $\Omega$ has a unique element $\bar{x}$ if and only if it is a solution of the following variational inequality:

$$
\bar{x} \in K, \quad\langle\nabla \varphi(\bar{x}), x-\bar{x}\rangle=\left\langle A^{*}\left(I-P_{D}\right) A \bar{x}, x-\bar{x}\right\rangle \geq 0, \quad x \in K,
$$

\section{Springer}

(0) 2013 Zegeye and Shahzad; licensee Springer. This is an Open Access article distributed under the terms of the Creative Commons Attribution License (http://creativecommons.org/licenses/by/2.0), which permits unrestricted use, distribution, and reproduction in any medium, provided the original work is properly cited. 
where $A^{\prime \prime}$ is the adjoint of $A$. In addition, inequality (1.3) can be rewritten as

$$
\bar{x} \in K, \quad\left\langle\bar{x}-\gamma A^{\prime \prime}\left(I-P_{D}\right) A \bar{x}-\bar{x}, x-\bar{x}\right\rangle \leq 0, \quad x \in K,
$$

where $\gamma>0$ is any positive scalar. Using the nature of projection, (1.4) is equivalent to the fixed point equation

$$
\bar{x}=P_{K}\left(\bar{x}-\gamma A^{*}\left(I-P_{D}\right) A \bar{x}\right) .
$$

Recall that a point $\bar{x} \in K$ is said to be a fixed point of $T$ if $T(\bar{x})=\bar{x}$. We denote the set of fixed points of $T$ by $F(T)$, i.e., $F(T):=\{\bar{x} \in K: T \bar{x}=\bar{x}\}$. Therefore, finding a solution to the split feasibility problem (1.1) is equivalent to finding the minimum-norm fixed point of the mapping $x \mapsto P_{K}\left(x-\gamma A^{*}\left(I-P_{D}\right) A x\right)$.

Motivated by the above split feasibility problem, we study the general case of finding the minimum-norm fixed point of an asymptotically nonexpansive self-mapping $T$ on $K$; that is, we find a minimum-norm fixed point of $T$ which satisfies

$$
\bar{x} \in F(T) \quad \text { such that }\|\bar{x}\|=\min \{\|x\|: x \in F(T)\} .
$$

Let $K$ be a nonempty subset of a real Hilbert space $H$; a mapping $T: K \rightarrow K$ is said to be nonexpansive if $\|T x-T y\| \leq\|x-y\|$ for all $x, y \in K$ and it is called asymptotically nonexpansive if there exists a sequence $\left\{k_{n}\right\} \subset[1, \infty)$ with $k_{n} \rightarrow 1$, as $n \rightarrow \infty$, such that

$$
\left\|T^{n} x-T^{n} y\right\| \leq k_{n}\|x-y\|, \quad \forall x, y \in K, \text { and } n \geq 1 .
$$

The class of asymptotically nonexpansive mappings was introduced as a generalization of the class of nonexpansive mappings by Goebel and Kirk [4] who proved that if $K$ is a nonempty closed convex bounded subset of a real uniformly convex Banach spaces which includes Hilbert spaces as a special case and $T$ is an asymptotically nonexpansive selfmapping of $K$, then $T$ has a fixed point.

Let $T: K \rightarrow K$ be a nonexpansive mapping. For a given $u \in K$ and a given $t \in(0,1)$, define a contraction $T_{t}: K \rightarrow K$ by

$$
T_{t} x=(1-t) u+t T x, \quad x \in K
$$

By the Banach contraction principle, it yields a fixed point $z_{t} \in K$ of $T_{t}$, i.e., $z_{t}$ is the unique solution of the equation

$$
z_{t}=(1-t) u+t T z_{t} .
$$

In [5], Browder proved that, as $t \rightarrow 1, z_{t}$ converges strongly to the nearest point projection of $u$ onto $F(T)$.

In [6], Halpern introduced an explicit iteration scheme $\left\{x_{n}\right\}$ (which was referred to as Halpern iteration) defined by

$$
x_{n+1}=\alpha_{n} u+\left(1-\alpha_{n}\right) T x_{n} .
$$


He proved that, as $n \rightarrow \infty,\left\{x_{n}\right\}$ converges strongly to the fixed point of a nonexpansive self-mapping $T$ that is closest to $u$ provided that $\left\{\alpha_{n}\right\}$ satisfies (i) $\lim _{n \rightarrow \infty} \alpha_{n}=0$, (ii) $\sum \alpha_{n}=$ $\infty$ and (iii) $\lim _{n \rightarrow \infty} \frac{\alpha_{n}}{\alpha_{n+1}}=0$. Wittmann [7] also showed that the sequence $\left\{x_{n}\right\}$ defined by

$$
x_{0}=u \in K, \quad x_{n+1}=a_{n+1} u+\left(1-a_{n+1}\right) T x_{n}, \quad n \geq 1,
$$

converges strongly to the element of $F(T)$ which is nearest to $u$ under certain conditions on $\left\{a_{n}\right\} \subset(0,1)$.

Moreover, using the idea of Browder [5], Shioji and Takahashi [8] studied the following scheme for an approximating fixed point of an asymptotically nonexpansive mapping. Let $T$ be an asymptotically nonexpansive mapping from $K$ into itself with $F(T)$ nonempty. Then they proved that the sequence generated by

$$
x_{0}=u \in K, \quad x_{n}=a_{n} u+\left(1-a_{n}\right) \frac{1}{n+1} \sum_{j=0}^{n} T^{j} x_{n}, \quad n \geq 1,
$$

where $\left\{a_{n}\right\} \subset(0,1)$ satisfies certain conditions, converges strongly to the element of $F(T)$ which is nearest to $u$. Shioji and Takahashi [8] also studied an explicit scheme for asymptotically nonexpansive mappings. They showed that the sequence $\left\{x_{n}\right\}$ defined by

$$
x_{0}=u \in K, \quad x_{n+1}=b_{n} u+\left(1-b_{n}\right) \frac{1}{n+1} \sum_{j=0}^{n} T^{j} x_{n}, \quad n \geq 1,
$$

where $\left\{b_{n}\right\} \subset(0,1)$ satisfies certain conditions, converges strongly to the element of $F(T)$ which is nearest to $u$.

Several authors have extended the above results either to a more general Banach spaces or to a more general class of mappings (see, e.g., [9-18]).

It is worth mentioning that the methods studied above are used to approximate the fixed point of $T$ which is closest to the point $u \in K$. These methods can be used to find the minimum-norm fixed point $x^{*}$ of $T$ if $0 \in K$. If, however, $0 \notin K$, any of the methods above fails to provide the minimum-norm fixed point of $T$.

In connection with the iterative approximation of the minimum-norm fixed point of a nonexpansive self-mapping $T$, Yang et al. [19] introduced an explicit scheme given by

$$
x_{n+1}=\beta T x_{n}+(1-\beta) P_{K}\left[\left(1-\alpha_{n}\right) x_{n}\right], \quad n \geq 1 .
$$

They proved that under appropriate conditions on $\left\{\alpha_{n}\right\}$ and $\beta$, the sequence $\left\{x_{n}\right\}$ converges strongly to the minimum-norm fixed point of $T$ in real Hilbert spaces.

More recently, Yao and Xu [20] have also shown that the explicit scheme $x_{n+1}=P_{K}((1-$ $\left.\left.\alpha_{n}\right) T x_{n}\right), n \geq 1$, converges strongly to the minimum-norm fixed point of a nonexpansive self-mapping $T$ provided that $\left\{\alpha_{n}\right\}$ satisfies certain conditions.

A natural question arises whether we can extend the results of Yang et al. [19] and Yao and $X u[20]$ to a class of mappings more general than nonexpansive mappings or not.

Let $K$ be a closed convex subset of a real Hilbert space $H$ and let $T_{i}: K \rightarrow K, i=1,2, \ldots, N$ be a finite family of asymptotically nonexpansive mappings. 
It is our purpose in this paper to introduce an explicit iteration process which converges strongly to the common minimum-norm fixed point of $\left\{T_{i}: i=1,2, \ldots, N\right\}$. Our theorems improve several results in this direction.

\section{Preliminaries}

In what follows, we shall make use of the following lemmas.

Lemma 2.1 Let $H$ be a real Hilbert space. Then, for any given $x, y \in H$, the following inequality holds:

$$
\|x+y\|^{2} \leq\|x\|^{2}+2\langle y, x+y\rangle .
$$

Lemma 2.2 [21] Let E be a real Hilbert space and $B_{R}(0)$ be a closed ball of $H$. Then, for any given subset $\left\{x_{0}, x_{1}, \ldots, x_{N}\right\} \subset B_{r}(0)$ and for any positive numbers $\alpha_{0}, \alpha_{1}, \ldots, \alpha_{N}$ with $\sum_{i=0}^{N} \alpha_{i}=1$, we have that

$$
\left\|\alpha_{0} x_{0}+\alpha_{1} x_{1}+\alpha_{2} x_{2}+\cdots+\alpha_{N} x_{N}\right\|^{2}=\sum_{i=0}^{N} \alpha_{i}\left\|x_{i}\right\|^{2}-\sum_{0 \leq i, j \leq N} \alpha_{i} \alpha_{j}\left\|x_{i}-x_{j}\right\|^{2} .
$$

Lemma 2.3 [22] Let $K$ be a closed and convex subset of a real Hilbert space $H$. Let $x \in H$. Then $x_{0}=P_{K} x$ if and only if

$$
\left\langle z-x_{0}, x-x_{0}\right\rangle \leq 0, \quad \forall z \in K .
$$

Lemma 2.4 [23] Let $H$ be a real Hilbert space, $K$ be a closed convex subset of $H$ and $T$ : $K \rightarrow K$ be an asymptotically nonexpansive mapping, then $(I-T)$ is demiclosed at zero, i.e., if $\left\{x_{n}\right\}$ is a sequence in $K$ such that $x_{n} \rightarrow x$ and $T x_{n}-x_{n} \rightarrow 0$, as $n \rightarrow \infty$, then $x=T(x)$.

Lemma 2.5 [24] Let $\left\{a_{n}\right\}$ be a sequence of nonnegative real numbers satisfying the following relation:

$$
a_{n+1} \leq\left(1-\alpha_{n}\right) a_{n}+\alpha_{n} \delta_{n}, \quad n \geq n_{0},
$$

where $\left\{\alpha_{n}\right\} \subset(0,1)$, and $\left\{\delta_{n}\right\} \subset R$ satisfying the following conditions: $\lim _{n \rightarrow \infty} \alpha_{n}=0$, $\sum_{n=1}^{\infty} \alpha_{n}=\infty$, and $\lim \sup _{n \rightarrow \infty} \delta_{n} \leq 0$, as $n \rightarrow \infty$. Then $\lim _{n \rightarrow \infty} a_{n}=0$.

Lemma 2.6 [25] Let $\left\{a_{n}\right\}$ be a sequence of real numbers such that there exists a subsequence $\left\{n_{i}\right\}$ of $\{n\}$ such that $a_{n_{i}}<a_{n_{i}+1}$ for all $i \in \mathbb{N}$. Then there exists a nondecreasing sequence $\left\{m_{k}\right\} \subset \mathbb{N}$ such that $m_{k} \rightarrow \infty$ and the following properties are satisfied by all (sufficiently large) numbers $k \in \mathbb{N}$ :

$$
a_{m_{k}} \leq a_{m_{k}+1} \text { and } a_{k} \leq a_{m_{k}+1} \text {. }
$$

In fact, $m_{k}=\max \left\{j \leq k: a_{j}<a_{j+1}\right\}$.

Proposition 2.7 Let $H$ be a real Hilbert space, let $K$ be a closed convex subset of $H$, and let $T$ be an asymptotically nonexpansive mapping from $K$ into itself. Then $F(T)$ is closed and convex. 
Proof Clearly, the continuity of $T$ implies that $F(T)$ is closed. Now, we show that $F(T)$ is convex. For $x, y \in F(T)$ and $t \in(0,1)$, put $z=t x+(1-t) y$. Now, we show that $z=T(z)$. In fact, we have

$$
\begin{aligned}
\left\|z-T^{n} z\right\|^{2}= & \|z\|^{2}-2\left\langle z, T^{n} z\right\rangle+\left\|T^{n} z\right\|^{2} \\
= & \|z\|^{2}-2\left\langle t x+(1-t) y, T^{n} z\right\rangle+\left\|T^{n} z\right\|^{2} \\
= & \|z\|^{2}-2 t\left\langle x, T^{n} z\right\rangle-2(1-t)\left\langle y, T^{n} z\right\rangle+\left\|T^{n} z\right\|^{2} \\
= & \|z\|^{2}+t\left\|x-T^{n} z\right\|^{2}+(1-t)\left\|y-T^{n} z\right\|^{2}-t\|x\|^{2}-(1-t)\|y\|^{2} \\
\leq & \|z\|^{2}+t k_{n}^{2}\|x-z\|^{2}+(1-t) k_{n}^{2}\|y-z\|^{2}-t\|x\|^{2}-(1-t)\|y\|^{2} \\
\leq & \|z\|^{2}+t k_{n}^{2}\langle x-z, x-z\rangle+(1-t) k_{n}^{2}\langle y-z, y-z\rangle \\
& -t\|x\|^{2}-(1-t)\|y\|^{2} \\
\leq & \left(k_{n}^{2}-1\right)\left[t\|x\|^{2}+(1-t)\|y\|^{2}+\|z\|^{2}\right],
\end{aligned}
$$

and hence, since $k_{n} \rightarrow 1$ as $n \rightarrow \infty$, we get that $\lim _{n \rightarrow \infty}\left\|z-T^{n} z\right\|^{2}=0$, which implies that $\lim _{n \rightarrow \infty} T^{n} z=z$. Now, by the continuity of $T$, we obtain that $z=\lim _{n \rightarrow \infty} T^{n} z=$ $\lim _{n \rightarrow \infty} T\left(T^{n-1} z\right)=T\left(\lim _{n \rightarrow \infty} T^{n-1} z\right)=T(z)$. Hence, $z \in F(T)$ and that $F(T)$ is convex.

\section{Main result}

We now state and proof our main theorem.

Theorem 3.1 Let $K$ be a nonempty, closed and convex subset of a real Hilbert space $H$. Let $T_{i}: K \rightarrow K$ be asymptotically nonexpansive mappings with sequences $\left\{k_{n, i}\right\}$ for each $i=1,2, \ldots, N$. Assume that $F:=\bigcap_{i=1}^{N} F\left(T_{i}\right)$ is nonempty. Let $\left\{x_{n}\right\}$ be a sequence generated by

$$
\left\{\begin{array}{l}
x_{1} \in K, \quad \text { chosen arbitrarily, } \\
y_{n}=P_{K}\left[\left(1-\alpha_{n}\right) x_{n}\right] \\
x_{n+1}=\beta_{n, 0} x_{n}+\sum_{i=1}^{N} \beta_{n, i} T_{i}^{n} y_{n}, \quad n \geq 1,
\end{array}\right.
$$

where $\alpha_{n} \in(0,1)$ such that $\lim _{n \rightarrow \infty} \alpha_{n}=0, \lim _{n \rightarrow \infty} \frac{\left(k_{n, i}^{2}-1\right)}{\alpha_{n}}=0$, for each $i \in\{1,2, \ldots, N\}$ and $\sum_{n=1}^{\infty} \alpha_{n}=\infty,\left\{\beta_{n, i}\right\} \subset[a, b] \subset(0,1)$ for $i=1,2, \ldots, N$, satisfying $\beta_{n, 0}+\beta_{n, 1}+\cdots+\beta_{n, N}=1$ for each $n \geq 1$. Then $\left\{x_{n}\right\}$ converges strongly to the common minimum-norm point of $F$.

Proof Let $x^{*} \in P_{F} 0$. Let $k_{n}:=\max \left\{k_{n, i}: i=1,2, \ldots, N\right\}$. Then from (3.1) and asymptotical nonexpansiveness of $T_{i}$, for each $i \in\{1,2, \ldots, N\}$, we have that

$$
\begin{aligned}
\left\|y_{n}-x^{*}\right\| & =\left\|P_{C}\left[\left(1-\alpha_{n}\right) x_{n}\right]-P_{K} x^{*}\right\| \\
& \leq\left\|\left(1-\alpha_{n}\right) x_{n}-x^{* \prime}\right\| \\
& =\left\|\alpha_{n}\left(0-x^{*}\right)+\left(1-\alpha_{n}\right)\left(x_{n}-x^{*}\right)\right\| \\
& \leq \alpha_{n}\left\|x^{*}\right\|+\left(1-\alpha_{n}\right)\left\|x_{n}-x^{*}\right\|,
\end{aligned}
$$


and

$$
\begin{aligned}
\left\|x_{n+1}-x^{*}\right\| & =\left\|\beta_{n, 0} x_{n}+\sum_{i=1}^{N} \beta_{n, i} T_{i}^{n} y_{n}-x^{*}\right\| \\
& \leq \beta_{n, 0}\left\|x_{n}-x^{*}\right\|+\sum_{i=1}^{N} \beta_{n, i}\left\|T_{i}^{n} y_{n}-x^{*}\right\| \\
& \leq \beta_{n, 0}\left\|x_{n}-x^{*}\right\|+\left(1-\beta_{n, 0}\right) k_{n}\left\|y_{n}-x^{*}\right\| \\
& \leq \beta_{n, 0}\left\|x_{n}-x^{*}\right\|+\left(1-\beta_{n, 0}\right) k_{n}\left[\alpha_{n}\left\|x^{*}\right\|+\left(1-\alpha_{n}\right)\left\|x_{n}-x^{*}\right\|\right] \\
& \leq\left[\beta_{n, 0}+\left(1-\beta_{n, 0}\right) k_{n}\left(1-\alpha_{n}\right)\right]\left\|x_{n}-x^{*}\right\|+\left[\left(1-\beta_{n, 0}\right) k_{n} \alpha_{n}\right]\left\|x^{*}\right\| \\
& \leq \delta_{n}\left\|x^{*}\right\|+\left[1-(1-\epsilon) \delta_{n}\right]\left\|x_{n}-x^{*}\right\|,
\end{aligned}
$$

where $\delta_{n}=\left(1-\beta_{n, 0}\right) k_{n} \alpha_{n}$, since there exists $N_{0}>0$ such that $\frac{\left(k_{n}-1\right)}{\alpha_{n}} \leq \epsilon k_{n}$ for all $n \geq N_{0}$ and for some $\epsilon>0$ satisfying $(1-\epsilon) \delta_{n} \leq 1$. Thus, by induction,

$$
\left\|x_{n+1}-x^{*}\right\| \leq \max \left\{\left\|x_{0}-x^{*}\right\|,(1-\epsilon)^{-1}\left\|x^{*}\right\|\right\}, \quad \forall n \geq N_{0},
$$

which implies that $\left\{x_{n}\right\}$ and hence $\left\{y_{n}\right\}$ is bounded. Moreover, from (3.2) and Lemma 2.1, we obtain that

$$
\begin{aligned}
\left\|y_{n}-x^{*}\right\|^{2} & =\left\|P_{K}\left[\left(1-\alpha_{n}\right) x_{n}\right]-P_{K} x^{*}\right\|^{2} \\
& \leq\left\|\alpha_{n}\left(0-x^{*}\right)+\left(1-\alpha_{n}\right)\left(x_{n}-x^{*}\right)\right\|^{2} \\
& \leq\left(1-\alpha_{n}\right)\left\|x_{n}-x^{*}\right\|^{2}-2 \alpha_{n}\left\langle x^{*}, y_{n}-x^{*}\right\rangle .
\end{aligned}
$$

Furthermore, from (3.1), Lemma 2.2 and asymptotical nonexpansiveness of $T_{i}$, for each $i=1,2, \ldots, N$, we have that

$$
\begin{aligned}
\left\|x_{n+1}-x^{*}\right\|^{2}= & \left\|\beta_{n, 0} x_{n}+\sum_{i=1}^{N} \beta_{n, i} T_{i}^{n} y_{n}-x^{*}\right\|^{2} \\
\leq & \beta_{n, 0}\left\|x_{n}-x^{*}\right\|^{2}+\sum_{i=1}^{N} \beta_{n, i}\left\|T_{i}^{n} y_{n}-x^{*}\right\|^{2} \\
& -\sum_{i=1}^{N} \beta_{n, 0} \beta_{n, i}\left\|x_{n}-T_{i}^{n} y_{n}\right\|^{2} \\
\leq & \beta_{n, 0}\left\|x_{n}-x^{*}\right\|^{2}+\left(1-\beta_{n, 0}\right) k_{n}^{2}\left\|y_{n}-x^{*}\right\|^{2} \\
& -\sum_{i=1}^{N} \beta_{n, 0} \beta_{n, i}\left\|x_{n}-T_{i}^{n} y_{n}\right\|^{2},
\end{aligned}
$$

which implies, using (3.4), that

$$
\begin{aligned}
\left\|x_{n+1}-x^{*}\right\|^{2} \leq & \beta_{n, 0}\left\|x_{n}-x^{*}\right\|^{2}+\left(1-\beta_{n, 0}\right) k_{n}^{2}\left[\left(1-\alpha_{n}\right)\left\|x_{n}-x^{*}\right\|^{2}\right. \\
& \left.-2 \alpha_{n}\left\langle x^{*}, y_{n}-x^{*}\right\rangle\right]-\sum_{i=1}^{N} \beta_{n, 0} \beta_{n, i}\left\|x_{n}-T_{i}^{n} y_{n}\right\|^{2}
\end{aligned}
$$




$$
\begin{aligned}
\leq & \left(1-\theta_{n}\right)\left\|x_{n}-x^{*}\right\|^{2}-2 \theta_{n}\left\langle x^{*}, y_{n}-x^{*}\right\rangle+\left(k_{n}^{2}-1\right) M \\
& -\sum_{i=1}^{N} \beta_{n, 0} \beta_{n, i}\left\|x_{n}-T_{i}^{n} y_{n}\right\|^{2} \\
\leq & \left(1-\theta_{n}\right)\left\|x_{n}-x^{*}\right\|^{2}-2 \theta_{n}\left\langle x^{*}, y_{n}-x^{*}\right\rangle+\left(k_{n}^{2}-1\right) M
\end{aligned}
$$

for some $M>0$, where $\theta_{n}:=\alpha_{n}\left(1-\beta_{n, 0}\right)$ for all $n \in N$.

Now, we consider the following two cases.

Case 1. Suppose that there exists $n_{0} \in \mathbb{N}$ such that $\left\{\left\|x_{n}-x^{*}\right\|\right\}$ is non-increasing for all $n \geq n_{0}$. In this situation, $\left\{\left\|x_{n}-x^{*}\right\|\right\}$ is convergent. Then from (3.5), we have that $\sum_{i=1}^{N} \beta_{n, 0} \beta_{n, i}\left\|x_{n}-T_{i}^{n} y_{n}\right\|^{2} \rightarrow 0$, which implies that

$$
x_{n}-T_{i}^{n} y_{n} \rightarrow 0, \quad \text { as } n \rightarrow \infty,
$$

for each $i \in\{1,2, \ldots, N\}$. Moreover, from (3.1) and (3.7) and the fact that $\alpha_{n} \rightarrow 0$, we get that

$$
\left\|x_{n+1}-x_{n}\right\|=\beta_{n, 1}\left\|T_{1}^{n} y_{n}-x_{n}\right\|+\cdots+\beta_{n, N}\left\|T_{N}^{n} y_{n}-x_{n}\right\| \rightarrow 0,
$$

and

$$
\begin{aligned}
\left\|y_{n}-x_{n}\right\| & =\left\|P_{C}\left[\left(1-\alpha_{n}\right) x_{n}\right]-P_{k} x_{n}\right\| \\
& \leq\left\|-\alpha_{n} x_{n}\right\| \rightarrow 0
\end{aligned}
$$

as $n \rightarrow \infty$ and hence

$$
\left\|y_{n+1}-y_{n}\right\| \leq\left\|y_{n+1}-x_{n+1}\right\|+\left\|x_{n+1}-x_{n}\right\|+\left\|x_{n}-y_{n}\right\| \rightarrow 0,
$$

as $n \rightarrow \infty$. Furthermore, from (3.7) and (3.9), we get that

$$
\left\|y_{n}-T_{i}^{n} y_{n}\right\| \leq\left\|y_{n}-x_{n}\right\|+\left\|x_{n}-T_{i}^{n} y_{n}\right\| \rightarrow 0, \quad \text { as } n \rightarrow \infty .
$$

Therefore, since

$$
\begin{aligned}
\left\|y_{n}-T_{i} y_{n}\right\| \leq & \left\|y_{n}-y_{n+1}\right\|+\left\|y_{n+1}-T_{i}^{n+1} y_{n+1}\right\|+\left\|T_{i}^{n+1} y_{n+1}-T_{i}^{n+1} y_{n}\right\| \\
& +\left\|T_{i}^{n+1} y_{n}-T_{i} y_{n}\right\|, \\
\leq & \left\|y_{n}-y_{n+1}\right\|+\left\|y_{n+1}-T_{i}^{n+1} y_{n+1}\right\|+k_{n+1}\left\|y_{n+1}-y_{n}\right\| \\
& +\left\|T_{i}\left(T_{i}^{n} y_{n}\right)-T_{i} y_{n}\right\|,
\end{aligned}
$$

we have from (3.10), (3.11), (3.12) and uniform continuity of $T_{i}$ that

$$
\left\|y_{n}-T_{i} y_{n}\right\| \rightarrow 0, \quad \text { as } n \rightarrow \infty \text {, for each } i=1,2, \ldots, N \text {. }
$$

Let $\left\{y_{n_{k}}\right\}$ be a subsequence of $\left\{y_{n}\right\}$ such that

$$
\limsup _{n \rightarrow \infty}\left\langle x^{*}, y_{n}-x^{*}\right\rangle=\lim _{k \rightarrow \infty}\left\langle x^{*}, y_{n_{k}}-x^{*}\right\rangle,
$$


and $y_{n_{k}} \rightarrow z$. Then from (3.9), we have that $x_{n_{k}} \rightarrow z$. Therefore, by Lemma 2.3, we obtain that

$$
\limsup _{n \rightarrow \infty}\left\langle x^{\prime \prime}, y_{n}-x^{\prime \prime}\right\rangle=\lim _{k \rightarrow \infty}\left\langle x^{\prime \prime}, y_{n_{k}}-x^{\prime \prime}\right\rangle=\left\langle x^{\prime \prime}, z-x^{\prime \prime}\right\rangle \geq 0 \text {. }
$$

Now, we show that $x_{n+1} \rightarrow x^{*}$, as $n \rightarrow \infty$. But from (3.13) and Lemma 2.4, we get that $z \in F\left(T_{i}\right)$ for each $i \in\{1,2, \ldots, N\}$ and hence $z \in \bigcap_{i=1}^{N} F\left(T_{i}\right)$. Then from (3.6), we get that

$$
\begin{aligned}
\left\|x_{n+1}-x^{*}\right\|^{2} \leq & \left(1-\theta_{n}\right)\left\|x_{n}-x^{*}\right\|^{2}-2 \theta_{n}\left\langle x^{*}, y_{n}-x^{*}\right\rangle \\
& +\left(k_{n}^{2}-1\right) M
\end{aligned}
$$

for some $M>0$. But note that $\theta_{n}$ satisfies $\lim _{n} \theta_{n}=0$ and $\sum_{n=1}^{\infty} \theta_{n}=\infty$. Thus, it follows from (3.15) and Lemma 2.5 that $\left\|x_{n}-x^{*}\right\| \rightarrow 0$, as $n \rightarrow \infty$. Consequently, $x_{n} \rightarrow x^{*}$.

Case 2. Suppose that there exists a subsequence $\left\{n_{i}\right\}$ of $\{n\}$ such that

$$
\left\|x_{n_{i}}-x^{*}\right\|<\left\|x_{n_{i}+1}-x^{*}\right\|
$$

for all $i \in \mathbb{N}$. Then by Lemma 2.6, there exists a nondecreasing sequence $\left\{m_{k}\right\} \subset \mathbb{N}$ such that $m_{k} \rightarrow \infty,\left\|x_{m_{k}}-x^{*}\right\| \leq\left\|x_{m_{k}+1}-x^{*}\right\|$ and $\left\|x_{k}-x^{*}\right\| \leq\left\|x_{m_{k}+1}-x^{*}\right\|$ for all $k \in \mathbb{N}$. Then from (3.5) and the fact that $\theta_{n} \rightarrow 0$, we have

$$
\begin{aligned}
& \sum_{i=1}^{N} \beta_{m_{k}, 0} \beta_{m_{k}, i}\left\|x_{m_{k}}-T_{i}^{m_{k}} y_{m_{k}}\right\|^{2} \\
& \quad \leq\left\|x_{m_{k}}-x^{*}\right\|^{2}-\left\|x_{m_{k}+1}-x^{* *}\right\|^{2}+\theta_{m_{k}}\left\|x_{m_{k}}-x^{*}\right\|^{2} \\
& \quad-2 \theta_{m_{k}}\left\langle x^{*}, y_{m_{k}}-x^{*}\right\rangle+\left(k_{m_{k}}-1\right) M \rightarrow 0, \quad \text { as } k \rightarrow \infty .
\end{aligned}
$$

This implies that $x_{m_{k}}-T_{i}^{m_{k}} y_{m_{k}} \rightarrow 0$, as $k \rightarrow \infty$. Thus, following the method of Case 1, we obtain that $x_{m_{k}}-y_{m_{k}} \rightarrow 0$ and $y_{m_{k}}-T_{i} y_{m_{k}} \rightarrow 0$ as $k \rightarrow \infty$ for each $i=1,2, \ldots, N$ and hence there exists $z^{\prime} \in F$ such that

$$
\limsup _{n \rightarrow \infty}\left\langle x^{*}, y_{n}-x^{*}\right\rangle=\lim _{k \rightarrow \infty}\left\langle x^{*}, y_{n_{k}}-x^{*}\right\rangle=\left\langle x^{*}, z^{\prime}-x^{*}\right\rangle \geq 0
$$

Then from (3.6), we get that

$$
\begin{aligned}
\left\|x_{m_{k}+1}-x^{*}\right\|^{2} \leq & \left(1-\theta_{m_{k}}\right)\left\|x_{m_{k}}-x^{*}\right\|^{2}-2 \theta_{m_{k}}\left\langle x^{*}, y_{m_{k}}-x^{*}\right\rangle \\
& +\left(k_{m_{k}}^{2}-1\right) M .
\end{aligned}
$$

Since $\left\|x_{m_{k}}-x^{*}\right\| \leq\left\|x_{m_{k}+1}-x^{*}\right\|$, (3.17) implies that

$$
\begin{aligned}
\theta_{m_{k}}\left\|x_{m_{k}}-x^{*}\right\|^{2} \leq & \left\|x_{m_{k}}-x^{*}\right\|^{2}-\left\|x_{m_{k}+1}-x^{*}\right\|^{2}-2 \theta_{m_{k}}\left\langle x^{*}, y_{m_{k}}-x^{*}\right\rangle \\
& +\left(k_{m_{k}}^{2}-1\right) M \\
\leq & -2 \theta_{m_{k}}\left\langle x^{*}, y_{m_{k}}-x^{*}\right\rangle+\left(k_{m_{k}}^{2}-1\right) M .
\end{aligned}
$$


In particular, since $\theta_{m_{k}}>0$, we have that

$$
\left\|x_{m_{k}}-x^{*}\right\|^{2} \leq-2\left\langle x^{*}, y_{m_{k}}-x^{*}\right\rangle+\frac{\left(k_{m_{k}}^{2}-1\right)}{\theta_{m_{k}}} M .
$$

Thus, from (3.16) and the fact that $\frac{\left(k_{m_{k}}^{2}-1\right)}{\theta_{m_{k}}} \rightarrow 0$, we obtain that $\left\|x_{m_{k}}-x^{*}\right\| \rightarrow 0$ as $k \rightarrow \infty$. This together with (3.17) gives $\left\|x_{m_{k}+1}-x^{*}\right\| \rightarrow 0$ as $k \rightarrow \infty$. But $\left\|x_{k}-x^{*}\right\| \leq\left\|x_{m_{k}+1}-x^{*}\right\|$ for all $k \in \mathbb{N}$, thus we obtain that $x_{k} \rightarrow x^{*}$. Therefore, from the above two cases, we can conclude that $\left\{x_{n}\right\}$ converges strongly to a point $x^{*}$ of $F$ which is the common minimumnorm fixed point of the family $\left\{T_{i}, i=1,2, \ldots, N\right\}$ and the proof is complete.

If in Theorem 3.1 we assume that $N=1$, then we get the following corollary.

Corollary 3.2 Let $K$ be a nonempty, closed and convex subset of a real Hilbert space $H$. Let $T: K \rightarrow K$ be an asymptotically nonexpansive mapping with a sequence $\left\{k_{n}\right\}$. Assume that $F(T)$ is nonempty. Let $\left\{x_{n}\right\}$ be a sequence generated by

$$
\left\{\begin{array}{l}
x_{1} \in C, \quad \text { chosen arbitrarily, } \\
y_{n}=P_{K}\left[\left(1-\alpha_{n}\right) x_{n}\right], \\
x_{n+1}=\beta_{n} x_{n}+\left(1-\beta_{n}\right) T^{n} y_{n}, \quad n \geq 1,
\end{array}\right.
$$

where $\alpha_{n} \in(0,1)$ such that $\lim _{n \rightarrow \infty} \alpha_{n}=0, \lim _{n \rightarrow \infty} \frac{\left(k_{n}^{2}-1\right)}{\alpha_{n}}=0$ and $\sum_{n=1}^{\infty} \alpha_{n}=\infty,\left\{\beta_{n}\right\} \subset$ $[a, b] \subset(0,1)$ for each $n \geq 1$. Then $\left\{x_{n}\right\}$ converges strongly to the minimum-norm fixed point of $T$.

If in Theorem 3.1 we assume that each $T_{i}$ is nonexpansive for $i=1,2, \ldots, N$, then the method of proof of Theorem 3.1 provides the following corollary.

Corollary 3.3 Let $K$ be a nonempty, closed and convex subset of a real Hilbert space $H$. Let $T_{i}: K \rightarrow K$ be nonexpansive mappings with $F:=\bigcap_{i=1}^{N} F\left(T_{i}\right)$ nonempty. Let $\left\{x_{n}\right\}$ be a sequence generated by

$$
\left\{\begin{array}{l}
x_{1} \in K, \quad \text { chosen arbitrarily, } \\
y_{n}=P_{K}\left[\left(1-\alpha_{n}\right) x_{n}\right], \\
x_{n+1}=\beta_{n, 0} x_{n}+\sum_{i=1}^{N} \beta_{n, i} T_{i} y_{n}, \quad n \geq 1,
\end{array}\right.
$$

where $\alpha_{n} \in(0,1)$ such that $\lim _{n \rightarrow \infty} \alpha_{n}=0$ and $\sum_{n=1}^{\infty} \alpha_{n}=\infty,\left\{\beta_{n, i}\right\} \subset[a, b] \subset(0,1)$, for $i=$ $1,2, \ldots, N$, satisfying $\beta_{n, 0}+\beta_{n, 1}+\cdots+\beta_{n, N}=1$ for each $n \geq 1$. Then $\left\{x_{n}\right\}$ converges strongly to the common minimum-norm point of $F$.

If in Corollary 3.3 we assume that $N=1$, then we have the following corollary.

Corollary 3.4 Let $K$ be a nonempty, closed and convex subset of a real Hilbert space $H$. Let $T: K \rightarrow K$ be a nonexpansive mapping with $F(T)$ nonempty. Let $\left\{x_{n}\right\}$ be a sequence 
generated by

$$
\left\{\begin{array}{l}
x_{1} \in K, \quad \text { chosen arbitrarily, } \\
y_{n}=P_{K}\left[\left(1-\alpha_{n}\right) x_{n}\right], \\
x_{n+1}=\beta_{n} x_{n}+\left(1-\beta_{n}\right) T y_{n}, \quad n \geq 1,
\end{array}\right.
$$

where $\alpha_{n} \in(0,1)$ such that $\lim _{n \rightarrow \infty} \alpha_{n}=0$ and $\sum_{n=1}^{\infty} \alpha_{n}=\infty,\left\{\beta_{n}\right\} \subset[a, b] \subset(0,1)$ for each $n \geq 1$. Then $\left\{x_{n}\right\}$ converges strongly to the minimum-norm point of $F(T)$.

\section{Applications}

In this section, we study the problem of finding a minimizer of a continuously Fréchetdifferentiable convex functional which has the minimum norm in Hilbert spaces.

Let $K$ be a closed convex subset of a real Hilbert space $H$. Consider the minimization problem given by

$$
\min _{x \in K} \varphi(x)
$$

and $\varphi: K \rightarrow \mathbb{R}$ be a continuously Fréchet-differentiable convex functional. Let $\Omega$, the solution set of (4.1), be nonempty; that is,

$$
\Omega:=\left\{z \in K: \varphi(z)=\min _{x \in K} \varphi(x)\right\} \neq \emptyset .
$$

It is known that a point $z \in K$ is a solution of (4.1) if and only if the following optimality condition holds:

$$
z \in K, \quad\langle\nabla \varphi(z), x-z| \geq 0, \quad x \in K,
$$

where $\nabla \varphi(x)$ is the gradient of $\varphi$ at $x \in K$. It is also known that the optimality condition (4.3) is equivalent to the following fixed point problem:

$$
z=T_{\gamma}(z), \quad \text { where } T_{\gamma}:=P_{K}(I-\gamma \nabla \varphi)
$$

for all $\gamma>0$.

Now, we have the following corollary deduced from Corollary 3.2.

Corollary 4.1 Let $K$ be a closed convex subset of a real Hilbert space H. Let $\varphi$ be a continuously Fréchet-differentiable convex functional on $K$ such that $T_{\gamma}:=P_{K}(I-\gamma \nabla \varphi)$ is asymptotically nonexpansive with a sequence $\left\{k_{n}\right\}$ for some $\gamma>0$. Assume that the solution of the minimization problem (4.1) is nonempty. Let $\left\{x_{n}\right\}$ be a sequence generated by

$$
\left\{\begin{array}{l}
x_{1} \in K, \quad \text { chosen arbitrarily, } \\
y_{n}=P_{K}\left[\left(1-\alpha_{n}\right) x_{n}\right], \\
x_{n+1}=\beta_{n} x_{n}+\left(1-\beta_{n}\right)\left[P_{K}(I-\gamma \nabla \varphi)\right]^{n} y_{n}, \quad n \geq 1,
\end{array}\right.
$$

where $\alpha_{n} \in(0,1)$ such that $\lim _{n \rightarrow \infty} \alpha_{n}=0, \lim _{n \rightarrow \infty} \frac{\left(k_{n}^{2}-1\right)}{\alpha_{n}}=0$ and $\sum_{n=1}^{\infty} \alpha_{n}=\infty,\left\{\beta_{n}\right\} \subset$ $[a, b] \subset(0,1)$ for each $n \geq 1$. Then $\left\{x_{n}\right\}$ converges strongly to the minimum-norm solution of the minimization problem (4.1). 
Remark 4.2 Our results extend and unify most of the results that have been proved for this important class of nonlinear mappings. In particular, Theorem 3.1 improves Theorem 3.2 of Yang et al. [19] and of Yao and Xu [20] to a more general class of a finite family of asymptotically nonexpansive mappings.

\section{Competing interests}

The authors declare that they have no competing interests.

Authors' contributions

All authors contributed equally and significantly in writing this paper. All authors read and approved the final manuscript.

\section{Author details}

'Departement of Mathematics, University of Botswana, Pvt. Bag 00704, Gaborone, Botswana. ${ }^{2}$ Department of Mathematics, King Abdulaziz University, P.O. Box 80203, Jeddah, 21589, Saudi Arabia.

\section{Acknowledgements}

The second author gratefully acknowledges the sup- port provided by the Deanship of Scientific Research (DSR), King Abdulaziz University during this research.

Received: 21 September 2012 Accepted: 28 November 2012 Published: 2 January 2013

\section{References}

1. Censor, Y, Elfving, T: A multiprojection algorithm using Bregman projections in a product space. Numer. Algorithms 8 221-239 (1994)

2. Byrne, C: Iterative oblique projection onto convex subsets and the split feasibility problem. Inverse Probl. 18, 441-453 (2002)

3. Censor, Y, Bortfeld, T, Martin, B, Trofimov, A: A unified approach for inversion problem in intensity-modulated radiation therapy. Phys. Med. Biol. 51, 2353-2365 (2006)

4. Goebel, K, Kirk, WA: A fixed point theorem for asymptotically nonexpansive mappings. Proc. Am. Math. Soc. 35, 171-174 (1972)

5. Browder, FE: Convergence of approximants to fixed points of nonexpansive nonlinear mappings in Banach spaces. Arch. Ration. Mech. Anal. 24, 82-90 (1967)

6. Halpern, B: Fixed points of nonexpansive maps. Bull. Am. Math. Soc. 73, 957-961 (1967)

7. Wittmann, R: Approximation of fixed point of nonexpansive mappings. Arch. Math. 58, 486-491 (1992)

8. Shimizu, T, Takahashi, W: Strong convergence theorems for asymptotically nonexpansive semigroups in Hilbert spaces. Nonlinear Anal. 34, 87-99 (1998)

9. Bruck, RE, Kuczumow, T, Reich, S: Convergence of iterates of asymptotically nonexpansive mappings in Banach spaces with the uniform Opial property. Colloq. Math. 65, 169-179 (1993)

10. Lim, TC, Xu, HK: Fixed point theorems for asymptotically nonexpansive mappings. Nonlinear Anal. 22, 1345-1355 (1994)

11. Morales, $\mathrm{CH}$, Jung, JS: Convergence of paths for pseudo-contractive mappings in Banach spaces. Proc. Am. Math Soc. 128, 3411-3419 (2000)

12. Reich, S: Strong convergence theorems for resolvents of accretive operators in Banach spaces. J. Math. Anal. Appl. 75, 287-292 (1980)

13. Schu, J: Iterative construction of fixed points of asymptotically nonexpansive mappings. J. Math. Anal. Appl. 158, 407-413 (1991)

14. Schu, J: Weak and strong convergence of fixed points of asymptotically nonexpansive mappings. Bull. Aust. Math. Soc. 43, 153-159 (1991)

15. Shioji, N, Takahashi, W: A strong convergence theorem for asymptotically nonexpansive mappings in Banach spaces. Arch. Math. 72, 354-359 (1999)

16. Shioji, N, Takahashi, W: Strong convergence of averaged approximants for asymptotically nonexpansive mappings in Banach spaces. J. Approx. Theory 97, 53-64 (1999)

17. Takahashi, W, Ueda, Y: On Reich's strong convergence theorems for resolvents of accretive operators. J. Math. Anal. Appl. 104, 546-553 (1984)

18. Tan, KK, Xu, HK: Fixed point iteration processes for asymptotically nonexpansive mappings. Proc. Am. Math. Soc. 122, 733-739 (1994)

19. Yang, X, Liou, Y-C, Yao, Y: Finding minimum norm fixed point of nonexpansive mappings and applications. Math. Probl. Eng. 2011, Article ID 106450 (2011). doi:10.1155/2011/106450

20. Yao, Y, Xu, H-K: Iterative methods for finding minimum-norm fixed points of nonexpansive mappings with applications. Optimization 60, 645-658 (2011)

21. Zegeye, $\mathrm{H}$ : A hybrid iteration method for equilibrium, variational inequality problems and common fixed point problems in Banach spaces. Nonlinear Anal. 72(3-4), 2136-2146 (2010)

22. Takahashi, W: Nonlinear Functional Analysis-Fixed Point Theory and Applications. Yokohama Publishers, Yokohama (2000)

23. Chang, SS, Cho, YJ, Zhou, H: Demi-closed principle and weak convergence problems for asymptotically nonexpansive mappings. J. Korean Math. Soc. 38, 1245-1260 (2001)

24. Ohara, JG, Pillay, P, Xu, HK: Iterative approaches to convex feasibility problems in Banach spaces. Nonlinear Anal. 64 2022-2042 (2006) 
25. Maingé, PE: Strong convergence of projected subgradient methods for nonsmooth and nonstrictly convex minimization. Set-Valued Anal. 16, 899-912 (2008)

doi:10.1186/1687-1812-2013-1

Cite this article as: Zegeye and Shahzad: Approximation of the common minimum-norm fixed point of a finite family of asymptotically nonexpansive mappings. Fixed Point Theory and Applications 2013 2013:1.

Submit your manuscript to a SpringerOpen ${ }^{\circ}$ journal and benefit from:

- Convenient online submission

- Rigorous peer review

- Immediate publication on acceptance

Open access: articles freely available online

- High visibility within the field

- Retaining the copyright to your article

Submit your next manuscript at $>$ springeropen.com 